\title{
Procuring Commodities: First Price Sealed Bid or English Auction?*
}

\author{
Jason Shachat \\ Wang Yanan Institute for Studies in Economics, Xiamen University \\ Jason.Shachat@gmail.com
}

First version: February 8, 2009

Current version: April 26, 2010

\begin{abstract}
I use laboratory experiments to examine the relative performance of the English auction (EA) and the first price sealed bid auction (FPA) when procuring a commodity. The mean and variance of prices are lower in the FPA than in the EA. Bids and prices in EA agree with game theoretic predictions while they don't in the FPA. To resolve these deviations found in the FPA, I consider a mixture model with three bidding rules: constant absolute mark-up, constant percentage mark-up, and strategic best response. A dynamic specification is estimated as a hidden Markov model. Initially about three quarters of the subjects are strategic bidders, but over time the number of strategic bidders falls to below sixty-five percent. There is a corresponding growth in those who bid a constant absolute mark-up above realized cost. This model provides an explanation of the dynamics of the mean and variance of price.
\end{abstract}

\footnotetext{
* Ernan Haruvy, J.Todd Swarthout, John Wooders, James C. Cox, Elana Katok, Mark Walker, Eric T Bradlow, an anonymous area editor, and especially two anonymous referees provided helpful comments on earlier drafts of the paper. The paper has benefitted from the comments of audience members in departmental seminars at Georgia State University, the University of Arizona, Xiamen University, and others. I would also like to thank the University of California, San Diego and the National University of Singapore for allowing me to conduct experiments in their facilities. I would also like to acknowledge the IBM TJ Watson Research Lab for financial support and use of their software. I thank Li-jia Wei for his outstanding research assistance.
} 


\section{Introduction}

I study the empirical properties of procurement costs and the behavior of participants in two basic procurement auctions, the first price sealed bid auction (FPA) and the English auction (EA). For currents purposes, commodities are goods for which the procurement official considers price the sole differentiating attribute among suppliers. The data come from a series of controlled laboratory experiments. The design of the experiments is such that inferences on performance, behavior, and dynamics are made without concern for estimating suppliers' costs or the procurement official's willingness-to-pay. A summary of the major findings is the mean and variance of procurement costs are lower in the FPA, price performance and bidding behavior are consistent with Nash equilibrium in the EA but not the FPA, there is discrete heterogeneity in bidding behavior in the FPA in which some subjects use simple mark-up strategies while others bid strategically, and with repeated participation in auctions the proportion of strategic bidders surprisingly decreases.

These results are relevant to the procurement official evaluating whether to switch from using traditional request for quotes to using dynamic reverse auctions. In a dynamic reverse auction potential suppliers can successively submit bids, observe the vector of all submitted bids (but not the bidders' identities), and in turn can lower their bids. When no supplier wishes to improve her bid, the auction closes and the procurer selects the supplier offering the best combination of price and non-price attributes. In the case of a commodity, the lowest bidding supplier wins and the dynamic reverse auction reduces to the EA. In a request for quote, each supplier submits a single price without knowledge of the prices submitted by other suppliers. Like the dynamic reverse auction, the procurer selects the supplier offering the best combination of price and non-price attributes. And in the case of commodities, the lowest bidding supplier wins - and receives a price equal to his bid - the request for quote reduces to a FPA. The commodity case is particularly relevant because this where many organizations choose to start dynamic reverse auction initiatives.

Many early users of dynamic reverse auctions reported savings of twenty percent or greater ${ }^{1}$, spurring a wave of adoption (Cafkin 2007 and Jap 2007). Since procurement organizations are usually responsible for sourcing a variety of goods, it is neither feasible nor

\footnotetext{
1 Two academic case studies reporting forty-three and twenty percent savings respectively are Kinney 2000 and Stein 2003.
} 
prudent to start using reverse auctions for all purchases. Given the belief that reverse auctions drive prices lower - the conventional wisdom advocated in industry, for example Purchasing.com 2001 and Chafkin 2007, and academic literatures, see Jap 2002 and Elmaghraby 2007 - is that a new adopter should start with commodities. This paper suggests the opposite is true: commodities are a poor choice for starting a reverse auction initiative and will likely result in higher prices on average and great price variability. Moreover, the distribution of prices in the EA experiments first order stochastically dominates the distribution of prices in the FPA experiments.

This study also contributes new insights into bidder behavior in independent private costs (or values in the case of a selling an object) auctions. ${ }^{2}$ The majority of behavioral research in auction has focused on the situation of selling goods rather than procurement (see Kagel 1995 and Kagel 2010 for extensive surveys). Most of this research, detailed later, demonstrates that while standard game theoretic predictions of performance and behavior are robust in the EA, they are some consistent deviations in the FPA. The same patterns hold true here, which is not surprising as the procurement environment is a mirror image of the sell auction one. However, the procurement setting does help uncover a new explanation for the deviations in the FPA. There is a discrete heterogeneity in the subjects' bidding rules.

I present an equilibrium model of bidding in the FPA based upon a mixture of strategic and rule-of-thumb bidders. Then a dynamic version of this model is estimated as a hidden Markov model: the latent variable is the rule a subject follows in each auction period. I estimate initially only three-quarters of the subjects follow a strategic bidding rule, and the remaining subjects follow either an absolute or a percentage mark-up rule. The estimated dynamics surprise as bidders becomes less strategic. After participating in a sequence of thirty auctions less than two-thirds of the subjects are bidding strategically, concurrently there is a corresponding rise in those who simply bid a small fixed absolute amount above costs. This dynamic model can explain the observed slow decay of the mean and variance of the winning auction price over time.

The paper proceeds as follows. The next section is a review of the relevant Marketing literatures. This is followed by the development of hypothesis regarding the performance of the

\footnotetext{
2 Independent and private here refers to the fact suppliers' costs are independent random variables for which the realizations are private information, and buyers' values are independent private random variables in auctions where potential buyer's compete to purchase a good.
} 
two auction types. Next, I present the details of the experimental design and features. Then, there is an empirical analysis of the price performance and bidder behavior in the experiments. After which there is a section on the theoretical mixture bidding model for the FPA and a subsequent section on the estimation results of a hidden Markov dynamic version of the model. I conclude the paper with comments on implications of the results and possible extensions.

\section{Related Marketing Literature on Auctions}

With the development of new information technologies, auctions are a growing part of the market allocation landscape in both final (Reilly 2000) and input (Jap 2002) goods markets. Correspondingly, the study of auctions and strategic interactions are enjoying a growing presence in academic Marketing research. Recurrent themes are different models of behavior are needed in strategic environments versus individual decision making - see Amaldoss et al. 2008, statistical modeling of auction data, the effectiveness of alternative auction formats, and the impact auctions have on relationships between firms in the supply chain.

Auction proliferation has generated vast amounts of data and led to new areas of empirical work. Many studies develop structural models of bidding behavior and use them to estimate properties of bidders and auctioneers. For example, Chan et al. 2007 and Song and Mela 2008 use structural models to estimate supply and demand from online auctions to sell goods. From name-your-own-price auctions for electronic goods, Abbas and Hahn 2010 estimated bidders' coefficients of relative risk attitude. Other studies have focused on formulating and estimating models that forecast bidding and prices in auctions. Jap and Naik 2008, and Bradlow and Park 2007 both present a reduced form models for forecasting bidding behavior in dynamic auctions. Park and Bradlow 2005 present a model that is structural and forecasts bidding behavior. The current study contributes to these efforts by introducing a new model of discrete heterogeneity and a dynamic statistical model of learning across auctions.

Information technology advances have made auction design variations quick and low cost to implement, and correspondingly spawned numerous studies comparing the performance of alternative auction rules and formats. The current study follows such a comparative static approach. Other examples, beyond the studies on procurement auctions review later, include Dholakia and Simonson’s 2005 study showing how including explicit reference points to competing prices raises auction prices, and Fay 2004 which shows that multiple versus single bid formats of name-your-own price auctions are empirically revenue equivalent. The large number 
and often varying in format concurrent auctions for the same products suggests analyzing competition between auction formats; this is in contrast to the traditional view of either/or comparative static analysis. Haruvy et al 2008 surveys this burgeoning literature.

A different strand of research considers the impact of reverse auctions in the larger context of buyer-supplier relationships within the supply chain. Jap 2003 and Jap 2007 document that adopting reverse auctions can reduce supplier performance when applied to an existing pool of suppliers and can damage log run relationship development. Jap and Haruvy 2008 analyze twelve different reverse auctions across various products and conduct pre and post auction surveys of the participant. They find that a supplier's incumbency status and willingness to make buyer specific investments are both inversely related to how aggressive they bid. And the counter also holds; the most aggressive bidders are less likely to make relationship investments. In this study, we demonstrate that the supplier's financial benefits have much greater variability in the reverse auction, and this is a potential source of the negative impact on buyer-supplier relationships.

\section{Analytical Analysis and Development of Hypotheses}

Let's start by defining a simple commodity procurement situation. A procurement official's task is to purchase an indivisible unit of a commodity as cheaply as possible. There are $n$ potential suppliers indexed by $i$. Each supplier can provide a unit of the commodity for the cost of $c_{i}$, which is incurred only if they supply the unit. The cost $c_{i}$ is only known by supplier $i$-i.e. it is private information, and will typically vary across suppliers. Suppliers are symmetric in that none has an ex ante cost advantage. Specifically, each of the supplier's costs are drawn independently from a uniform distribution on the interval $\left[c_{L}, c_{H}\right]$. A supplier will know his own realized costs, but only the distribution of the other suppliers' costs. The procurement official only knows that each supplier's cost is drawn independently from this uniform distribution.

We consider two sourcing methods for this scenario. In the adopted version of the EA an initial high price is selected and all $n$ suppliers are in the auction. Then the price gradually falls. At any point a supplier can irreversibly exit the auction. The number of remaining suppliers and current price are always publically posted. When the second to last supplier exits, leaving a sole remaining supplier, the auction closes. The last remaining supplier wins the auction and receives 

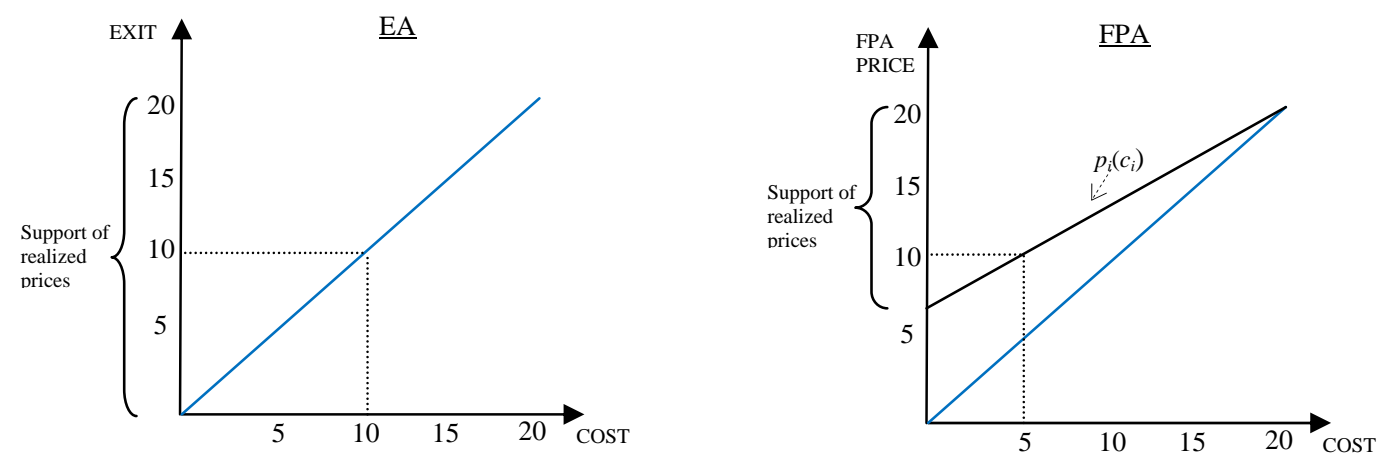

Figure 1: Nash Equilibrium Bidding Behavior

the closing auction price, $p$. The winning seller receives a profit of $p-c_{i}$, and all other suppliers receive zero profit. ${ }^{3}$

Game theoretic analysis - Vickrey 1961 - reveals that the supplier has a weakly dominant strategy: remain in the auction as long as the price is greater than the supplier's unit cost and exit when the price equals cost. ${ }^{4}$ The intuition is that all losing suppliers are driven to the point where their profit margin is zero, and thus revealing their true costs, before exiting the auction. Moreover, the supplier with the lowest realized cost wins the auction and receives a price equal to the second lowest realized cost.

In a FPA, each supplier privately submits a price. Then the procurement official purchases from the lowest priced supplier, and that supplier receives is paid a price equal to his bid. This procurement FPA is equivalent to a first price sealed bid auction to sell an indivisible unit. ${ }^{5}$ The pure strategy symmetric Nash Equilibrium of this RFQ calls for a supplier to submit a price according to the following function of realized costs and the number of potential suppliers, Vickrey 1961:

$$
p_{i}\left(c_{i}\right)=\frac{c_{H}+(n-1) c_{i}}{n} .
$$

\footnotetext{
${ }^{3}$ There are other formats of the reverse auction. For example, in an open outcry format individual suppliers can announce successively lower bids until there is no supplier willing to improve upon the current existing price. The supplier submitting the last price wins the auction at that price. In the strategic analysis, optimal bidder behavior is equivalent in the open outcry and version we describe.

${ }^{4}$ One can find standard arguments for this weakly dominant strategy in texts like (Krishner 2002). A weakly dominant strategy in this context means that regardless of the other suppliers' strategy there is never an instance in which the supplier can strictly increase his expected payoff by deviating from this strategy.

${ }^{5}$ To see the equivalence, define the supplier's private value as $c_{H}-c_{i}$, the potential amount of value he can offer below the highest possible cost, and define the bid as, $c_{H}-p_{i}$, the amount of value the supplier actually offers to the buyer.
} 
This pricing strategy has an interesting behavioral interpretation; a supplier's price is the expected second lowest realized cost conditional upon his cost being the lowest. Now consider the EA. The winning supplier, who has the lowest realized cost, receives the price equal to the second lowest realized cost. This is an example of the celebrated revenue equivalence theorem in auction theory, ${ }^{6}$ and forms our first hypothesis.

Hypothesis I: The expected prices in the FPA and the EA are the same.

To get a better insight on the revenue equivalence principle, let's consider an example with three suppliers whose costs are independent and uniformly distributed on the interval [0, 20]. In this case the expected value of the lowest, second lowest, and highest cost are five, ten, and fifteen respectively. Figure 1 depicts the expected outcome under the Nash equilibrium. In the EA, the winner's expected cost is five. Furthermore, the expected second lowest cost, and the corresponding auction price, is ten. In the FPA, we expect the winning supplier's cost is also five and for him to bid ten, the expected second lowest cost conditional upon five being the lowest.

Of course while the expected - or average - prices are the same, the distribution of prices is not. In the EA it is easy to see that that actual winning price can occur anywhere on the interval $[0,20]$. On the other hand, the support of possible prices is smaller in the FPA. If a supplier's realized cost is zero then conditional expectation of the second lowest cost is six and two-thirds, and this is the supplier's FPA bid. At the other extreme with a realized cost of twenty, the conditional expectation of the second lowest cost, and the corresponding quoted price, is twenty. Cleary the distribution of prices in the EA is a mean preserving spread of the prices in the FPA. In fact, Vickery (1962) shows that with independent and uniformly distributed costs and $n$ bidders the variance of the price in the EA is $\frac{2(n-1)}{(n+2)(n+1)^{2}}\left(c_{H}-c_{L}\right)^{2}$ and in the FPA is $\frac{(n-1)^{2}}{n(n+2)(n+1)^{2}}\left(c_{H}-c_{L}\right)^{2}$. So the variance in the EA price is greater than that of the FPA by a factor of $2 n / n-1$. This is our second hypothesis:

Hypothesis II: The variance of EAs prices is greater than that of the FPA.

With respect to the suppliers, the expected profit will be the same in both the EA and the FPA; the expected lowest cost less the expected second lowest cost multiplied by the probability

\footnotetext{
${ }^{6}$ The revenue equivalence theorem was first proven by Vickery 1961 and is applicable to our scenario. It was proven for a wider class of scenarios by Myerson 1981. For our concerns the version used here states that if sellers are risk neutral, have independent and symmetric costs, and payment is function of the bid only, then the FPA and the reverse auction will have the same expected price.
} 
of being the lowest cost supplier. In our example, this is $\$ 1.67$. However, the difference is the variance of expected payoff is much higher than for the procurement official. The variances for the supplier profit in the EA is $\frac{n}{(n+2)(n+1)^{2}}\left(c_{H}-c_{L}\right)^{2}$ and in the FPA is $\frac{1}{n(n+2)(n+1)^{2}}\left(c_{H}-c_{L}\right)^{2}$; the difference is a factor of $n^{2}$. The volatility of the supplier's profit is much greater than the volatility of the buyer's benefit. We summarize these observations with the following pair of hypotheses.

Hypothesis Ia: The expected profit of a supplier is the same in the FPA and the EA. Hypothesis IIa: The variance of a supplier's profit in a EAs prices is greater than that of the FPA.

I formulate the next hypothesis by relaxing the constraint that all suppliers are risk neutral. When entering into a procurement process the outcomes are uncertain to the suppliers. However, because of the weakly dominant strategy, risk aversion does not affect suppliers' predicted behavior or the resulting prices. This is not true for the FPA. Holt 1980 shows that if all suppliers have the same risk averse von Neumann-Morgenstern expected utility function, then there exists a symmetric Nash equilibrium in which the expected price is lower than that of the EA.

This issue is quite prominent in the experimental economics literature on single unit private value sealed bid sell auctions. Those experiments are a mirror image to the commodity procurement FPA. An auctioneer wishes to sell a single indivisible unit of a good and there are $n$ possible buyers. Each buyer draws an independent private valuation from a uniform distribution on the interval $\left[0, v_{H}\right]$. This valuation is an individual specific price that he can resell the object to the experimenter for. The symmetric Nash equilibrium bidding strategy for this auction is

$$
B\left(v_{i}\right)=\frac{n-1}{n} v_{i} .
$$

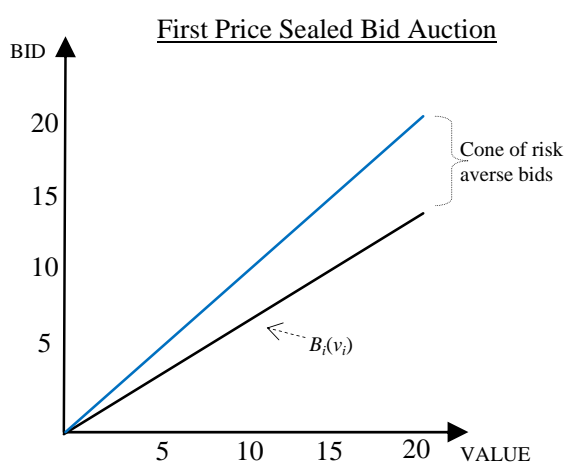

Figure 2: Nash Equilibrium FPA Sell Auction 
If we set the number of buyers to three and the highest possible valuation to twenty, we have the selling counterpart to our example. The equilibrium bidding function is depicted in Figure 2.

Early studies - such as Coppinger, Smith, and Titus 1980 and Cox, Roberson, and Smith 1982 - found that the vast majority of bids lay above the Nash equilibrium bidding line in Figure 2 and below the forty-five degree line at which bid equals value in the area labeled the cone of risk averse bids. Consequently, they found that the first price sealed bid auction provided the buyer with higher average prices than those received in the English outcry auction. Cox, Roberson, and Smith suggests that these choices are the result of heterogeneous risk attitudes amongst the bidders. ${ }^{7}$ Further they propose a Nash equilibrium model in which a bidder's risk attitude is characterized by a single parameter that is private information. ${ }^{8}$ Given Holt's theoretical model of the FPA with risk averse suppliers and the strong empirical evidence from experiments of first price sealed bid sellers auctions we offer the following hypothesis

Hypothesis III: The expected or average price in the FPA will be lower than in the EA.

Our FPA investigation provides a unique opportunity to conduct a powerful test amongst competing behavioral hypotheses in the private value first price sealed bid auction. Notice in Figure 2 that the Nash equilibrium bid function also corresponds to the behavioral rule always bid a fixed proportion of your realized value. If we allow for heterogeneous risk attitudes then any estimated linear bid function, which goes through the origin and has slope less than one, is consistent with both fixed proportion of realized value and a Nash Equilibrium bid functions. ${ }^{9}$

Now consider the FPA Nash equilibrium bid function depicted in Figure 1. In this case, these two behavioral rules generate quite distinct behavior. A Nash equilibrium bidder, demands zero margin when his has the worst (highest) cost realization, and his margin demanded, both proportional and absolute, increases as realized cost decreases. This pricing behavior is strikingly different from that of a supplier who simply demands a fixed percentage margin, i.e. their pricing

${ }^{7}$ Other alternative models to explain this observation have been recently proposed such as regret theory, Filiz and Ozbay 2007 and Engelbrecht-Wiggans and Katok 2006, and directional learning theory, Neugebauer 2006.

8 There have been numerous studies which have addressed the appropriateness of the risk aversion explanation; Kagel and Levin 2008 provide a survey of these criticisms.

9 Note that in the Holt model all bidders have the same risk attitude and would have the same bid function. Meanwhile, in the Cox, Roberson and Smith model subjects have heterogeneous risk attitudes and will have varying linear bidding strategies with one caveat. Above the threshold of the maximum possible bid of a risk neutral buyer, the bid function is strictly concave. 
strategy is simply $p_{i}\left(c_{i}\right)=(1+\rho) c_{i}$. In our data analysis, we also consider a third behavioral rule in which a supplier demands a constant absolute margin, or profit level. For this type of supplier his pricing function is of the form $p_{i}\left(c_{i}\right)=\alpha+c_{i}$. Later, a mixture model based upon three rules is formulated and estimated.

\section{Experimental Design and Procedures}

All experimental sessions were conducted at the Economics Laboratory at UCSD and at the NUS School of Business. All participants were either undergraduate or master level students at one of the two universities. FPA and EAs were conducted at both facilities. The number of participants in an experimental session consisted of some multiple of three between nine and eighteen. Experimental sessions lasted no more than one hour and subject earned between \$8 (S\$12) and \$60 (S\$89) inclusive of a show-up fee.

\begin{tabular}{ccccccc} 
Session & Treatment & Location & $\begin{array}{c}\text { Number } \\
\text { Subject }\end{array}$ & Rounds & $\begin{array}{c}\text { Minimum } \\
\text { Earnings }\end{array}$ & $\begin{array}{c}\text { Maximum } \\
\text { Earnings }\end{array}$ \\
\hline \hline 1 & FPA & UCSD & 15 & 32 & 16.72 & 52.62 \\
2 & FPA & UCSD & 15 & 32 & 11.00 & 58.98 \\
3 & FPA & UCSD & 15 & 32 & 13.23 & 42.45 \\
4 & FPA & NUS & 9 & 32 & 23.24 & 48.94 \\
5 & FPA & NUS & 18 & 32 & 21.60 & 55.72 \\
6 & EA & UCSD & 9 & 32 & 7.05 & 62.70 \\
7 & EA & NUS & 9 & 32 & 30.78 & 87.84 \\
8 & EA & NUS & 18 & 32 & 32.84 & 88.74
\end{tabular}

Table 1: Summary of experimental sessions

*Earnings are US\$ for UCSD sessions and S\$ for NUS sessions, the show-up fee is \$5 at UCSD and $\mathrm{S} \$ 10$ at NUS, the exchange rate at the time of the sessions was approximately $\$ 1=\mathrm{S} \$ 1.5$.

I adopted the simple previous three supplier example as the basis for our experiments. In a session, the subjects participated in series of thirty-two rounds of either FPA's or EA's. In each round, the subjects were randomly re-partitioned into a set of triads. The first two rounds were for practice; the subjects earned no money and the data is not reported. For the remaining rounds 
the participants' earnings were given in an experimental currency. The exchange rates were one experimental dollar to \$0.33 (or S\$0.50.) In total we conducted 720 FPA's and 360 EA's. 10

Participants made decisions through a personal computer running a custom designed software program, and in a partition designed to ensure private decisions. In the FPA, at the start of each period the subject is revealed his or her realized private cost (a new cost was drawn each period.) The subject was also shown the period number and the number of other subjects in the FPA. The subject was prompted to submit a price (restricted to be between zero and thirty), but could take as much time desired to do so. After all prices were submitted, the auction results were revealed. These results consisted of the bid submitted by the subject, the amount of the winning bid, and the subject's period profit. All of the information was then entered into a display, along with the cumulative profit, at the bottom of the computer screen for future reference. At the conclusion of the experiment, subjects were informed of their total earnings and paid that amount privately.

The EA experiment had the same procedures, except for the execution of auction. On the computer screen there was a display of the current auction price and a button that one could press to exit the auction. The auction started with an initial price of \$21. Then the price was decremented at the rate of ten cents every half a second. As auction participants exited the auction, subjects could observe the decrement of the displayed number of participants remaining in the auction. At the close of the auction their cost, exit price, period profits, and cumulative profits were entered in history viewing area.

\section{Data Analysis and Results}

We first address the relative performance of the two alternative procurement procedures, and observe that procurement costs are lower and less volatile in the FPA. For suppliers, average profits are higher, but at the same time, more volatile in the EA.

\footnotetext{
10 Due to the strong agreement of the data with the weakly dominant bidding strategy in the reverse auction I collected an unbalanced sample.
} 


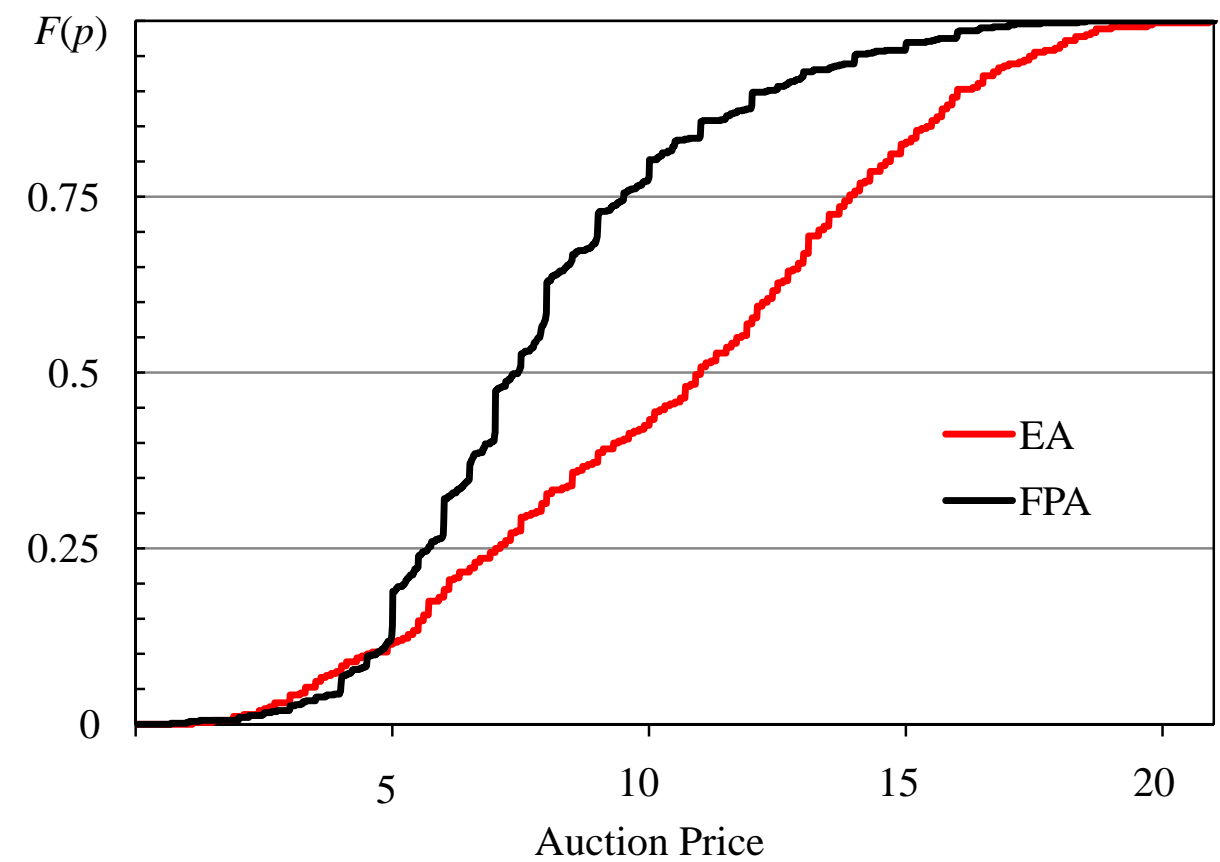

Figure 3: Empirical cumulative distribution functions of FPA and EA prices

Let's start by considering the distributions of realized FPA and EA prices. Figure 3 presents the empirical cumulative distribution functions of prices under the two different auction types. For now let's assume that each of the $m=720$ FPA prices is an independent realization from the continuous distribution $W_{\mathrm{FPA}}$ generating the empirical CDF $\bar{W}_{\mathrm{FPA}}$, and that each of the $n$ $=360 \mathrm{EA}$ prices is an independent realization from the continuous distribution $W_{\text {EA }}$ generating the empirical CDF $\bar{W}_{\mathrm{EA}}$. I test the hypothesis that these two distributions are equal, versus the alternative they are not, with the Kolmogorov-Smirnov two-sample test. The test-statistic is $\bar{S}=\max _{P}\left|\bar{W}_{\mathrm{FPA}}(p)-\bar{W}_{\mathrm{EA}}(p)\right|=0.372$, which has a p-value of essentially zero, and we reject that the underlying distribution of auction prices are the same. Casual inspection of Figure 3 also suggests that $W_{\mathrm{EA}}$ first order stochastically dominates $W_{\mathrm{FPA}}$, in other words for every $\mathrm{p}$ $W_{\mathrm{EA}}(p) \leq W_{\mathrm{FPA}}(p)$. Barret and Donald 2003 introduced a test for this hypothesis versus the alternative that for some $p, W_{\mathrm{EA}}(p)>W_{\mathrm{FPA}}(p)$. The test statistic is

$$
\bar{S}=\left(\frac{m n}{m+n}\right)^{1 / 2} \max _{P}\left(\bar{W}_{\mathrm{EA}}(p)-\bar{W}_{\mathrm{FPA}}(p)\right)=0.002 .
$$

The p-value of this test statistic is great than 0.999, we leads us not to reject the hypothesis of first order stochastic dominance. Under the first order stochastic dominance criteria in decision 
making (Seshadri et al 1991 and Levy 1992) the EA more strongly favors the suppliers rather than the procurement official.

$\underline{\text { Result 1: }}$ Procurement prices in the EA first order stochastically dominate those in the FPA.

\begin{tabular}{rcccc} 
& & & Mean Supplier & Supplier Profit \\
Mean Price & Price Variance & Profit & Variance \\
\cline { 2 - 5 } EA & $\underline{\mathbf{1 0 . 6 0}}$ & $\mathbf{1 9 . 1 1}$ & $\mathbf{1 . 6 8}$ & $\mathbf{1 0 . 6 7}$ \\
& $(0.230)$ & $\underline{10}$ & $\underline{1.67}$ & $\underline{15.03}$ \\
& $\mathbf{7 . 9 0}$ & $\mathbf{9 . 6 3}$ & $\mathbf{0 . 9 0}$ & $\mathbf{3 . 0 4}$ \\
FPA & $\underline{10}$ & $\underline{10.67}$ & $\underline{1.67}$ & $\underline{1.67}$ \\
& $(0.116)$ & {$[5.63,7.69]$} & $(0.037)$ & {$[1.50,1.84]$} \\
& & & & \\
Difference & $-25.5 \%$ & $-50.4 \%$ & $-46.3 \%$ & $-71.5 \%$
\end{tabular}

Table 2: Summary statistics on prices and profits

Inspecting the mean and variance of the prices reveals that FPA delivers lower cost and lower price volatility to the procurement official. Table 2 present the means and variances of the two price distributions and the differences in these values. The first column shows the mean, the standard error of the means, and the percentage difference in prices. Two-tailed $t$-tests lead us to reject that the EA mean price (5\% level of significance) and the FPA mean price (1\% level of significance) are equal to the risk neutral Nash equilibrium prediction of ten. Moreover, we reject that the mean prices are the same in favor of the hypothesis that the FPA mean price is lower by conducting a $t$-test for unequal variances (1\% level of significance.)

Result 2: Procurement prices are lower, 25.5\% in fact, for the FPA. We reject hypothesis I in favor of hypothesis III.

In the second column we report information for the variance on prices. Under the risk neutral Nash equilibrium bidding models, the variance of the prices in the EA and FPA are twenty and six and two-thirds respectively. We give the sample variances and beneath those we 
give bootstraps of the $95 \%$ confidence intervals of the variance under Nash equilibrium. ${ }^{11}$ We can't reject that the variance is equal to the predicted value in the EA, but we do reject this for the FPA as the estimated variance is well outside and above the confidence interval. When comparing the variances, we reject that hypothesis they are the same in favor of the hypothesis that the EA price have greater variance (Levin $F$-tests for heterogeneous variances at the $1 \%$ level of significance.) However, the price variance in the EA is only twice as large (i.e. the $-50.4 \%$ change noted in the table,) not triple as predicted in theory.

Result 3: Procurement costs are more volatile in the EA. Our experimental results are consistent with hypothesis II.

Thus, unless a procurement organization is very risk loving, the lower average price and lower price variability make the FPA the better method in the commodity situation.

What about the welfare of the suppliers? As we see in the third column, we can't reject ( $t$ test at $1 \%$ level of significance) that the mean supplier profit in the EA is equal to the theoretical value of 1.67. Average supplier profit in the FPA is $46.3 \%$ lower, and we reject these profits are the same as the risk neutral Nash equilibrium bidding and the empirical mean of the average profit in the EA experiments (both at the 1\% level of significance.) While suppliers actually do better on average in the EAs, the volatility of the payoffs are about two and a half times more volatile.

Result 4: Supplier's profits are higher in the EA rather than the FPA and we reject hypothesis Ia. And we also find these profits are more volatile in the EA as well - confirming hypothesis IIa.

The relative performances of the two procurements methods are most consistent with risk averse Nash Equilibrium models. These results show promise that the robustness of this type of model would extend to other type of procurement and supply chain activities. But this model is formulated as a description of individual level behavior. So, this robustness likely only holds if the model explains what happens at the individual level.

\footnotetext{
${ }^{11}$ Since the distribution of prices under Nash equilibrium in know to us and non-normal simple $t$-tests of the estimated variances are not valid. So, we bootstrap with 10,000 draws from the known distribution and then calculate the $95 \%$ confidence intervals for the theoretical values of the variance.
} 


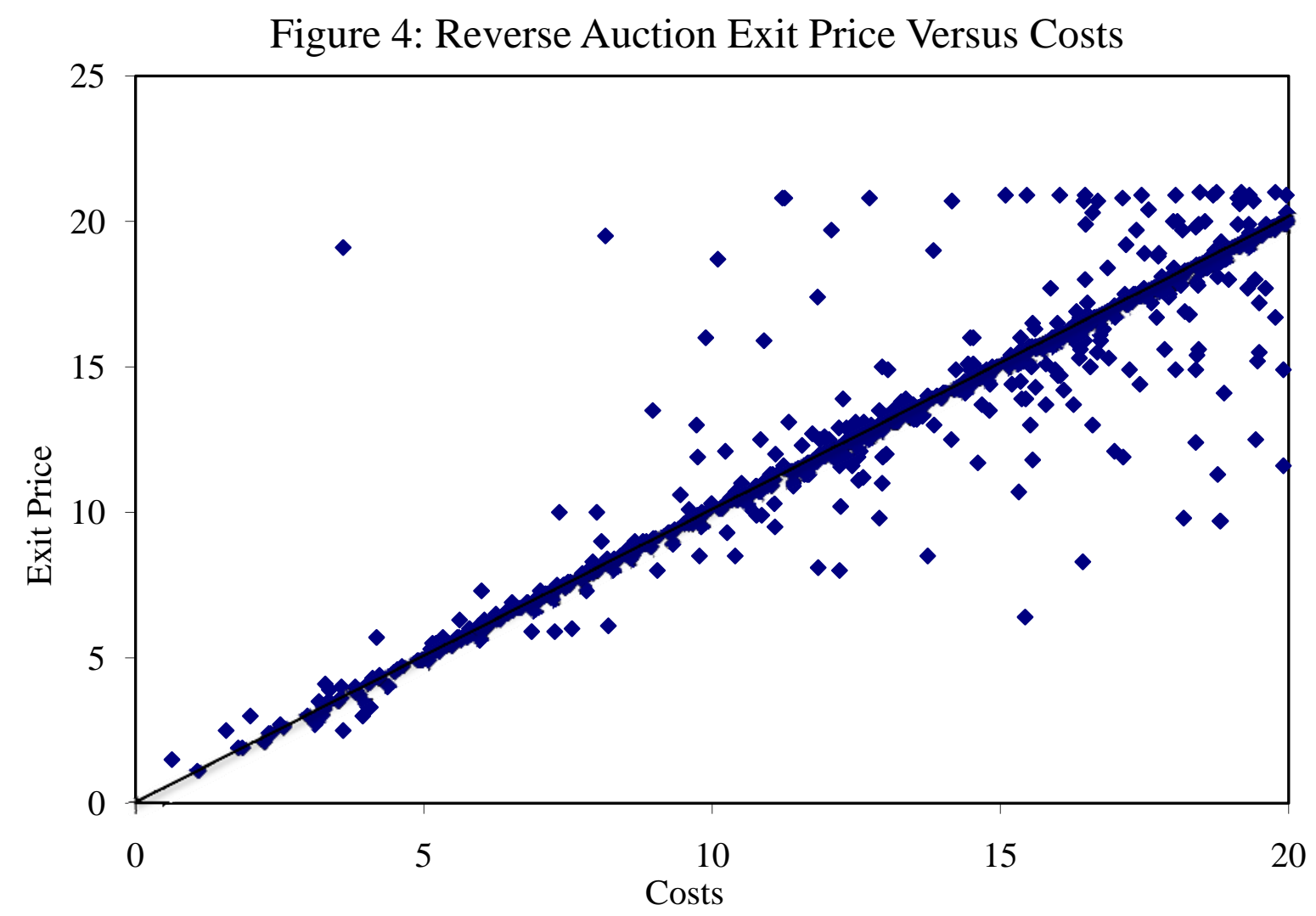

Risk aversion does not affect the weakly dominant strategy in the EA, and we should observe those who exit an auction do so at their true costs. Figure 4 plots seller's exit prices versus there realized costs. While much of the data does adhere closely to forty-five degree line as we would expect, there is a surprising amount that doesn't. Much of these occurrences are at high cost levels. There are a number of observations were a seller opts out as soon as possible when the auction opens at the price of $\$ 21$ : perhaps such a bidder is frustrated by receiving a high cost level? However, there is another story for the number of exit prices below cost. In most of these cases, subject remains in the auction while there are still two other remaining suppliers. Then, as soon as one of the other suppliers exits, this individual exits as well. To see the effect of how price determining bids depend upon costs, I plot the realized auction price versus the second lowest realized costs in Figure 5. Here one can see much crisper conformity with the forty-five degree line. To quantify this we present an OLS fitted trend line through the origin. The slope coefficient is essentially one and this regression explains over $93 \%$ of the variation as indicated by the $R^{2}$ statistic. 
Figure 5: Reverse Auction Price Versus Second Lowest Costs

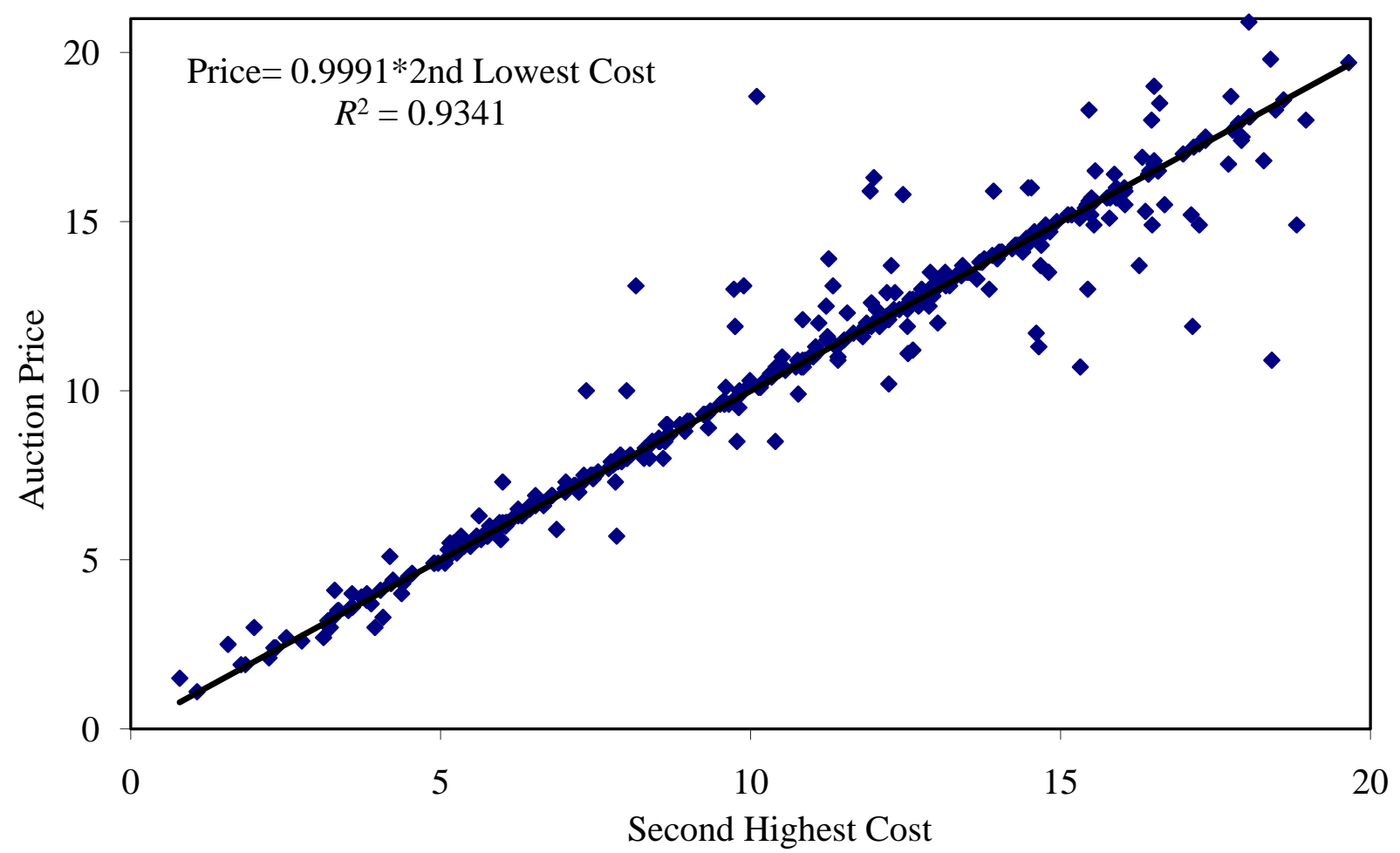

Figure 6: Sumitted RFQ Prices Versus Costs

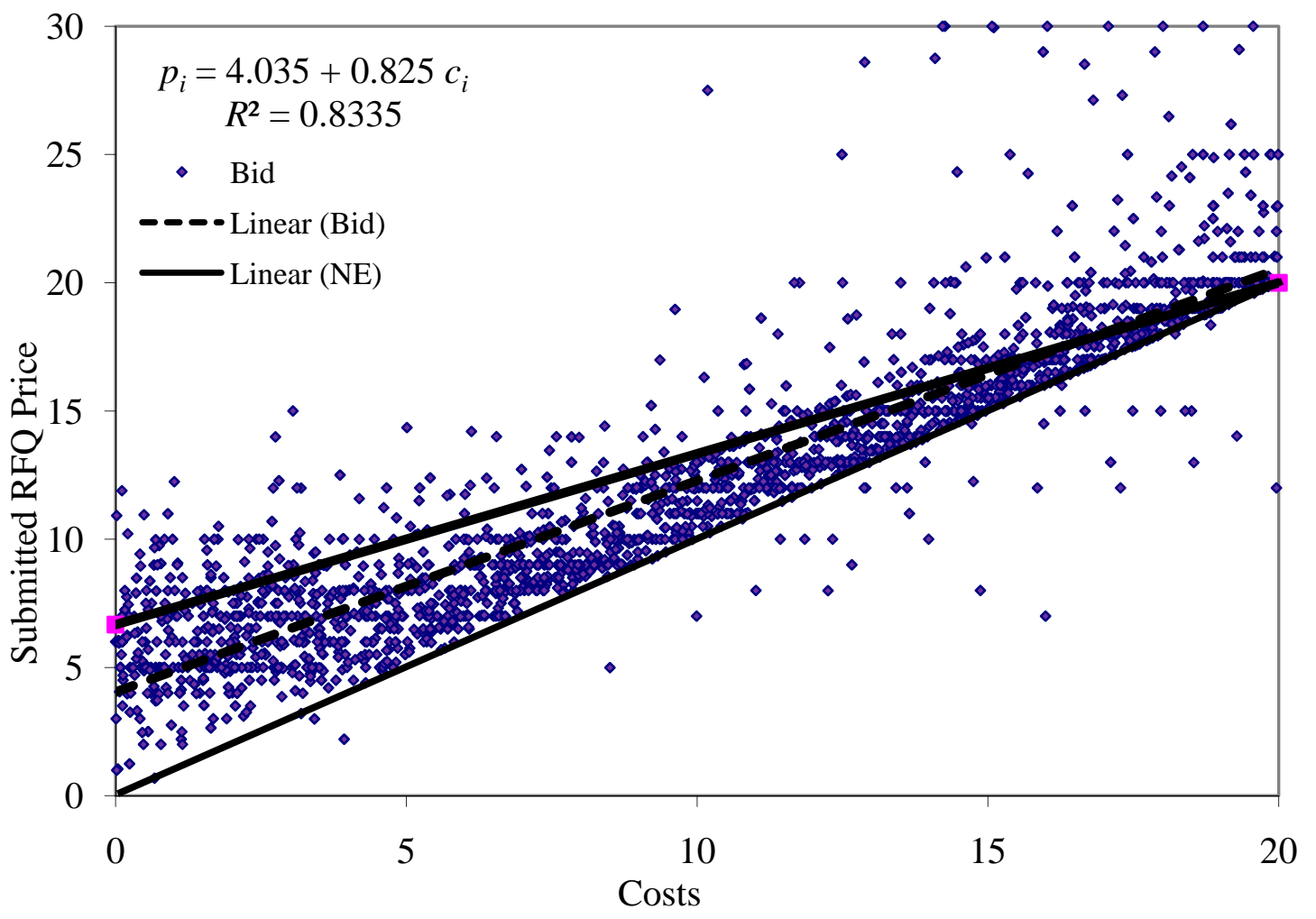


Now let's turn our attention to the individual subject behavior in the FPA sessions. Figure 6 displays the 2160 submitted FPA bids versus realized costs, the risk neutral Nash Equilibrium pricing function, the price equal to cost line (the forty-five degree line), and an OLS fitted line for the data. Clearly, the majority of bids are above cost but below the risk neutral Nash equilibrium price - just as a risk averse Nash model predicts. However, there are also a surprising amount of bids outside (particularly above) this cone of risk averse actions. I now proceed to formulate and estimate a model with discrete bidding rule heterogeneity that is consistent with this data.

\section{A Model of Sophisticated and Rule of Thumb Bidders.}

Consider a setting in which a supplier follows a rule $r$ which belongs to a set of rules $R=\{A M, P M, B R\}$. Let $\Pi$ denote a probability distribution on this set for which $\pi_{r}$ is the probability a supplier is a bidder of type $r$. An $A M$, or absolute mark-up, bidder always demands a fixed profit amount independent of his costs. In other words, $A M$ bidders price according to:

$$
b_{A M}\left(c_{i}\right)=c_{i}+\kappa,
$$

where $\kappa$ is the fixed absolute mark-up. A $P M$, or proportional mark-up, bidder always demands a fixed percentage margin based on realized costs. His bidding rule is:

$$
b_{P M}\left(c_{i}\right)=(1+\rho) c_{i},
$$

where $\rho$ is the proportional mark-up. A $B R$, or strategic best response, bidder selects a price that maximizes his expected utility given $\Pi$ conditional upon his realized cost. For now let's assume that a $B R$ bidder prices according to a strictly increasing bounded function, thus having an inverse, denoted $b_{B R}\left(c_{i}\right)$.

When a $B R$ bidder formulates his bidding strategy it's assumed that he knows the parameters $\Pi, \rho$, and $\kappa$; and that he also has the von Neumann-Morgenstern expected utility function $U(y)=\eta y^{1 / \eta}$, where $y$ is non-negative changes in wealth. If the $B R$ wins the FPA his change in wealth is his bid minus his cost, otherwise there is no change in wealth. The $B R$ bidder's expected utility is the utility of his profit times the probability of winning the FPA - the probability his bid is lower than all other bidders. This probability is 


$$
\begin{aligned}
& \operatorname{Pr}\left(p_{j} \leq p_{i}\right)=\left(1-\pi_{A M}-\pi_{P M}\right) \operatorname{Pr}\left(p_{j} \leq b_{B R}\left(c_{i}\right)\right)+\pi_{A M} \operatorname{Pr}\left(p_{j} \leq c_{i}+\kappa\right) \\
& \quad+\pi_{P M} \operatorname{Pr}\left(p_{j} \leq(1+\rho) c_{i}\right) .
\end{aligned}
$$

Since each of the three bidding rules has an inverse we can restate this probability, $F$ denotes the uniform distribution, as

$$
\begin{aligned}
\operatorname{Pr}\left(p_{j} \leq p_{i}\right)= & \left(1-\pi_{A M}-\pi_{P M}\right)\left[1-F\left(b_{B R}^{-1}\left(p_{j}\right)\right)\right]+\pi_{A M}\left[1-F\left(p_{j}-\kappa\right)\right] \\
& +\pi_{P M}\left[1-F\left(\frac{p_{j}}{1+\rho}\right)\right] .
\end{aligned}
$$

In an FPA with $N-1$ other suppliers, the probability of winning with a bid price $p_{j}$ is

$$
\operatorname{Pr}\left(p_{j} \leq p_{i}, i=1, \cdots, N-1\right)=\left[\operatorname{Pr}\left(p_{j} \leq p_{i}\right)\right]^{N-1}
$$

Thus the expected utility of a bid $p_{j}$ conditional on realized cost $c_{j}$ is

$$
\begin{aligned}
\mathrm{E}\left[U\left(p_{j} \mid c_{j}\right)\right] & =\eta\left(p_{i}-c_{i}\right)^{1 / \eta}\left[\left(1-\pi_{A M}-\pi_{P M}\right)\left(\frac{c_{H}-b_{B R}^{-1}\left(p_{j}\right)}{c_{H}-c_{L}}\right)+\pi_{A M}\left(\frac{c_{H}-\left(p_{j}-\kappa\right)}{c_{H}-c_{L}}\right)\right. \\
+ & \left.\pi_{P M}\left(\frac{c_{H}-p_{j} / 1+\rho}{c_{H}-c_{L}}\right)\right]^{N-1}
\end{aligned}
$$

The first order condition of maximizing expected utility with respect to the bid price is

$$
\begin{gathered}
\frac{1}{\eta}\left[\left(1-\pi_{A M}-\pi_{P M}\right)\left(c_{H}-b_{B R}^{-1}\left(p_{j}\right)\right)+\pi_{A M}\left(c_{H}-\left(p_{j}-\kappa\right)\right)+\pi_{P M}\left(c_{H}-\frac{p_{j}}{1+\rho}\right)\right] \\
-(N-1)\left(p_{i}-c_{i}\right)\left[\frac{\left(1-\pi_{A M}-\pi_{P M}\right)}{b_{B R}^{\prime}\left(p_{j}\right)}+\pi_{A M}+\frac{\pi_{P M}}{1+\rho}\right]=0 .
\end{gathered}
$$

Now if one assumes that all the $B R$ bidders are using the same bid function, the above expression reduces to the following differential equation, 


$$
\frac{C_{H}-c_{i}+\frac{\rho}{1+\rho} \pi_{P M} c_{i}+\pi_{A M} \kappa}{p_{i}-c_{i}}=\frac{\eta(N-1)\left(1-\pi_{A M}-\pi_{P M}\right)}{b_{B R}^{\prime}\left(p_{j}\right)}+(\eta(N-1)+1)\left(\pi_{A M}+\frac{\pi_{P M}}{1+\rho}\right) .
$$

The solution and $B R$ bidding function is

$$
b_{B R}\left(c_{i}\right)=\frac{\left(C_{H}+\pi_{A M} \kappa\right)(1+\rho)}{\left(1+\rho\left(1-\pi_{P M}\right)\right) M}+\frac{M-1}{M} * c_{i}, \text { where } M=\eta(N-1)+1 .
$$

There are several interesting things to note about the $B R$ bid function. It is linear in cost. The slope depends upon the parameter of the expected utility function and the number of other bidders. Most surprising is that the probabilities of the absolute and percentage mark-up bidders, and the size of these mark-ups, only affect the intercept term; changes in these values only vertically shift the $B R$ bid function.

The mean and variance of the winning FPA price depends upon the distribution of each supplier $i$ 's bid. This is given by

$$
Q(z)=\operatorname{Pr}\left(p_{i} \leq z\right)=\sum_{r \in R} \pi_{r} F\left(b_{r}^{-1}(z)\right),
$$

and the distribution of the winning, or minimum, bid is

$$
Q_{1}(z)=[1-Q(z)]^{N-1}
$$

When calculating the expectation and variance of the winning FPA price, it will involve piecewise integration of this function. The boundary points of these integrals depend upon the intersection points of the three bidding rules. Figure 7, depicts the scenario found in the subsequent data analysis.

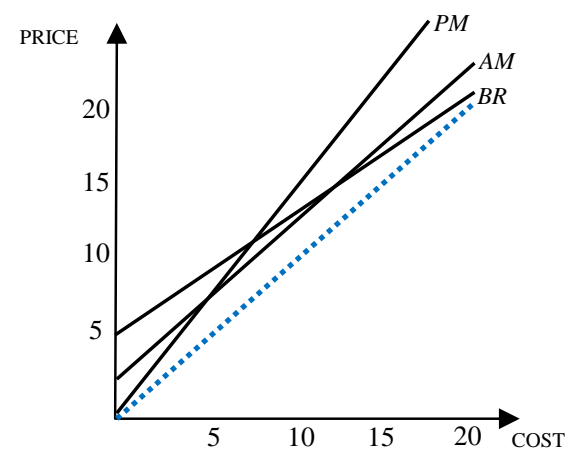

Figure 7: Crossing Pattern of Bidding Functions 


\section{Rule Switching Dynamics: Specification and Estimation of a Hidden Markov Model}

Given that subjects participate in repeated auctions, as suppliers likely do in practice, I explore the possibilities that individuals will adapt and switch bidding rules over time. I formulate such a process by assuming that there is an initial portion of subjects adopting each the three bidding rules. Then there is a stationary Markov process that governs the probabilities of switching from one rule to another. If a bidders following their adopted rules with some random noise, then the assignment of subjects to bidding rules is a latent variable. Such a state-space model with latent states is called a hidden Markov model (HMM). HMM's are a natural way to model dynamic phenomenon in Marketing (Netzer, Lattin, and Srinivasan 2008 study the relationships between charitable donors and institutions ) when subject passed through discrete paths (Hui, Fader, and Bradlow 2009 present a framework for general forms of path data) over time.

Consider the following stationary Marko process. Let $z_{i, t}$ be the rule used by subject $i$ in period $t$, and $z_{i}$ be the thirty element sequence of rules seller $i$ adopts over the course of the experiment. Define $\pi_{r 1}$ as the probability a seller follows rule $r$ in period $1, \Pi_{1}$ is the multinomial probability distribution these initial probabilities constitute, and let $A$ be the matrix of transition probabilities with element $a_{s r}$. In other words, the probability that a subject who uses rule $s$ in period $t-1$ transitions to rule $r$ in period $t, a_{s r}=\mathrm{P}\left(z_{i, t}=r \mid z_{i, t-1}=s\right)$. Also denote $\mu_{r t}$ as the proportion of the subjects who are using rule $r$ in period $t$. And finally let $\pi_{r t}$ be the period $t$ probability a randomly selected subject is using rule $r$ which is,

$\pi_{r t}=\sum_{s \in R} \mu_{s t-1} a_{s r}$

When a subject follows rule $r$ the price he submits is an independent random variable that follows a normal distribution $G$ with mean $b_{r}\left(c_{i t}\right)$ and rule specific variance $\sigma_{r}$. The probability densities of the three bidding rules are

$$
\begin{aligned}
& h_{A M}\left(p_{i t} \mid c_{i t} ; \kappa\right)=G\left(c_{i t}+\kappa, \sigma_{A M}^{2}\right) ; \\
& h_{P M}\left(p_{i t} \mid c_{i t} ; \rho\right)=G\left((1+\rho) c_{i t}, \sigma_{P M}^{2}\right) ; \text { and } \\
& h_{B R}\left(p_{i t} \mid c_{i t} ; \Pi_{t}, \kappa, \rho\right)=G\left(\frac{\left(C_{H}+\pi_{A M t} \kappa\right)(1+\rho)}{\left(1+\rho\left(1-\pi_{P M t}\right)\right) M}+\frac{M-1}{M} c_{i t}, \sigma_{B R}^{2}\right) .
\end{aligned}
$$


The set of parameters of this model is $\Theta=\left(\Theta_{M}, \Theta_{B}\right)$, where $\Theta_{M}$ is the set of variables governing the stochastic process of rule adoption, $\left\{\Pi_{1}, A\right\}$, and $\Theta_{\mathrm{B}}$ is set of parameters that determine the bidding rules $\left\{\kappa, \rho, \eta, \sigma_{r}\right\}$. The likelihood of subject $i$ 's sequence of prices conditional upon the parameters $\Theta$ and the realization of $z_{i}$ is

$L_{i}\left(p_{i 1}, \cdots, p_{i 30} \mid z_{i}, \theta\right)=\prod_{t=1}^{30} h_{z_{i 1}}\left(p_{i t} \mid c_{i t}, \theta\right)$,

and the likelihood of $z_{i}$ condition upon $\Theta_{\mathrm{B}}$ is

$L_{i}\left(z_{i} \mid \theta_{M}\right)=\pi_{z_{i 1}} \prod_{t=2}^{30} a_{z_{i t-1} z_{i t}}$.

I can express the likelihood of the joint sequences of bids and bidding rule adoption as

$L_{i}\left(p_{i 1}, \cdots, p_{i 30}, z_{i} \mid \theta\right)=L_{i}\left(p_{i 1}, \cdots, p_{i 30} \mid z_{i}, \theta\right) L_{i}\left(z_{i} \mid \theta_{M}\right)$.

However, since the realization state is not observable I need to integrate out the marginal likelihood of $z_{i}$ by summing over all possible sequences of rule adoption

$L_{i}\left(p_{i 1}, \cdots, p_{i 30} \mid \theta\right)=\sum_{z_{i} \in Z} L_{i}\left(p_{i 1}, \cdots, p_{i 30} \mid z_{i}, \theta\right) L_{i}\left(z_{i} \mid \theta_{M}\right)$

Finally the Likelihood for the whole sample is

$L(X \mid \theta)=\prod_{i=1}^{72} \sum_{z_{i} \in Z} L_{i}\left(p_{i 1}, \cdots, p_{i 30} \mid z_{i}, \theta\right) L_{i}\left(z_{i} \mid \theta_{M}\right)$.

A common way to find the parameter values which maximize $L(X \mid \theta)$ is to use the Baum-Welch algorithm, which is a special case of the $E M$-algorithm. ${ }^{12}$ The output of this algorithm provides posterior modes of $\Theta_{\mathrm{M}}$, an estimated most likely path $\widehat{z_{l}}$ for each subject, and maximum likelihood estimates of $\Theta_{\mathrm{G}}$.

However, there is one issue preventing the estimation of the model as specified: the intercept term of strategic bidding rule depends of the distribution over types and thus is a function of the parameters in $\Theta_{\mathrm{M}}$. To resolve this issue I change the specification of $b_{B R}$ to a fixed effect model

$b_{B R}\left(c_{i t}\right)=\sum_{d=1}^{30} I_{\langle d=t\rangle} \alpha_{t}+\frac{M-1}{M} c_{i t}$, where $M=\eta(N-1)+1$, and $I$

${ }^{12}$ For details on these two algorithms we refer the reader to the classic presentation in Rabiner 1989. 
is an indicator function. To check to appropriateness of this specification, I calculate the theoretical value of the intercept of the $B R$ bid function for each time period $t$ using the maximum likelihood estimated values of the mark-up and the proportions of subjects estimated to be using each rule in period $t$ according to the $\widehat{z_{l}}$. Subsequently, these values are compared to the estimated dummy variables.

\begin{tabular}{cccccc} 
Model & Intercept & t-stat & Slope & t-stat & $\sigma_{A M}^{2}$ \\
\hline \hline$A M$ & 0.80 & 37.36 & 1.00 & - & 0.50 \\
$P M$ & 0.00 & - & 1.30 & 10.93 & 5.27 \\
$B R$ & 4.43 & 25.59 & 0.79 & 35.54 & 1.30
\end{tabular}

Table 3: Hidden Markov model estimates of bidding rule parameters

Table 3 presents the maximum likelihood estimates of the parameters of each of the three bidding rules. Note all parameter estimates are significant. For the $A M$ rule, the estimated markup is a mere eighty cents, suggesting aggressive bidding to win the FPA. One the other hand, for the $P M$ rule the estimated mark-up is thirty percent over costs, suggesting aggressive bidding for a large profit. The standard error for this rule is much higher than the standard errors of the other two rules, symptomatic there could be heterogeneity in the percentage mark-ups used by individuals. For the $B R$ bidding rule, the inferred value of $\eta$ is 1.84 , which yields a constant coefficient of relative risk aversion of 0.56 - in line with the estimates from other studies of private value first price sealed bid auctions. ${ }^{13}$

\footnotetext{
${ }^{13}$ For example, consider some other estimates of constant coefficient of relative risk aversions of 0.67, 0.52, 0.48,
} and 0.57 respectively from Cox and Oaxaca 1996, Goeree et al 2002, Chen and Plott 1998, and Berg et al 2005. 


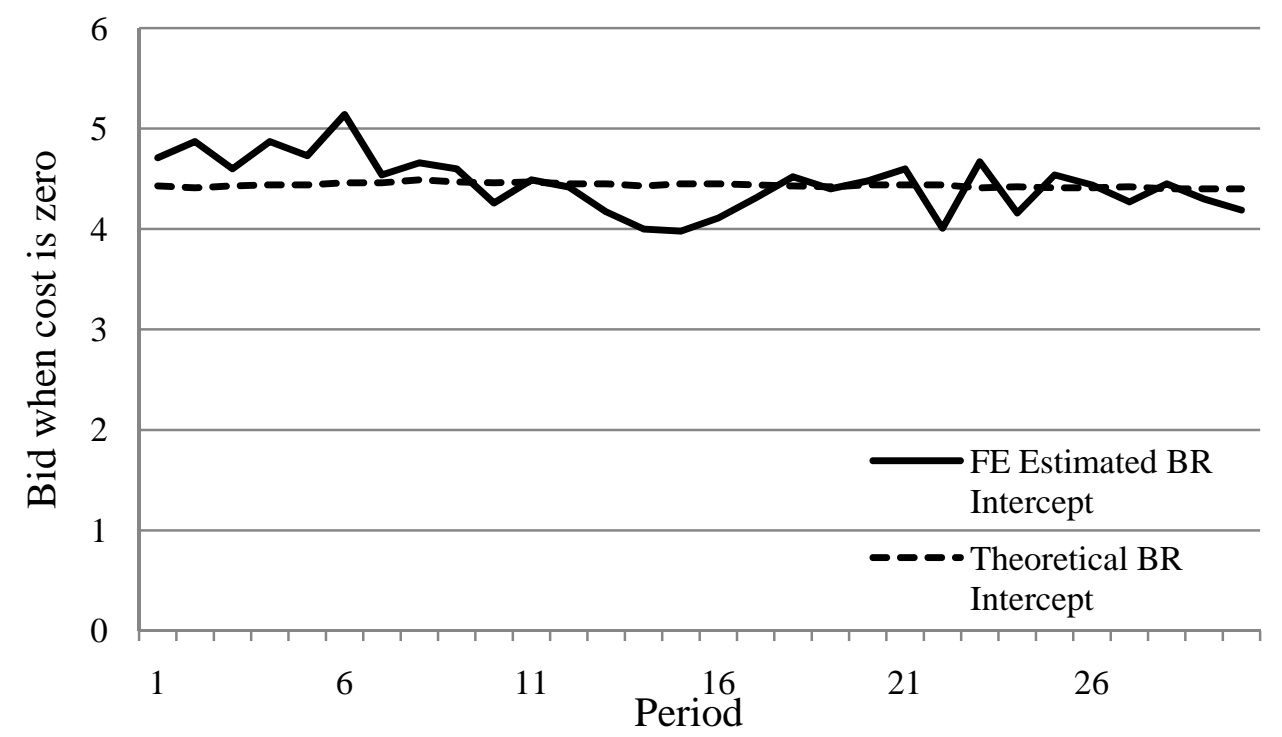

Figure 8: Theoretical values of the $B R$ rule intercept over time vs. Estimated Fixed Effects

Recall that instead of estimating the exact $B R$ bidding rule with non-linear constraints on the model parameters, I estimated a fixed effect model. Figure 8 presents a comparison of these estimated fixed effects versus the theoretical value of the $B R$ rule intercept based upon the estimates of the mark-up sizes and the estimated proportions of subjects using each rule each period. Visual inspection reveals that the theoretical value of the intercept varies little over time, and that the dummy variable model also does not vary a lot. In fact, only three of the fixed effects are significantly different than the mean effect. This suggests that there is little dramatic movement in the use of different rules over time. We now examine this more explicitly.

\begin{tabular}{c|c|c|c|}
\multicolumn{1}{c}{$z_{i t}=A M$} & $z_{i t}=P M$ & \multicolumn{1}{c}{$z_{i t}=B R$} \\
\cline { 2 - 4 }$z_{i t-1}=A M$ & 0.78 & 0.00 & 0.22 \\
\cline { 3 - 4 }$z_{i t-1}=P M$ & 0.00 & 0.87 & 0.13 \\
\cline { 3 - 4 }$z_{i t-1}=B R$ & 0.10 & 0.02 & 0.88 \\
\cline { 2 - 4 } & & & \\
\hline
\end{tabular}

Table 4: Posterior mode estimates of rule switching probabilities 
The posterior mode estimates of the Markov process parameters reveal a surprising amount of inertia in rule adoption, and rather than developing strategic sophistication the percentage of $B R$ bidders diminishes over time. The estimated initial distribution over the rules is $\widehat{\Pi}_{1}=\left(\hat{\pi}_{A M 1} \hat{\pi}_{P M 1}, \hat{\pi}_{B R 1}\right)=(0.12,0.14,0.74)$, and the estimated matrix of transition probabilities $\hat{A}$ is given in Table 4. There a several interesting results one can draw from this estimated Markov process. First, there is strong inertia in the rules subjects follow. The continuation probabilities range from seventy-eight to eighty-eight percent. Second, there is no switching between the two simple rules of thumbs. The only rule transitions are between $A M$ and $B R$, and $P M$ and $B R$. While it's not surprising subjects switch from simple mark-up price rules to the more strategically sophisticated strategy, it’s surprising that there are subjects who switch from the $B R$ rule to simple mark-up strategies. In these cases, it's mostly the absolute mark-up rule that is switched to. Why would someone make such a switch? A natural conjecture that estimated $A M$ rule has a small mark-up, and that following that rule will lead to more frequent wins in the auction. ${ }^{14}$

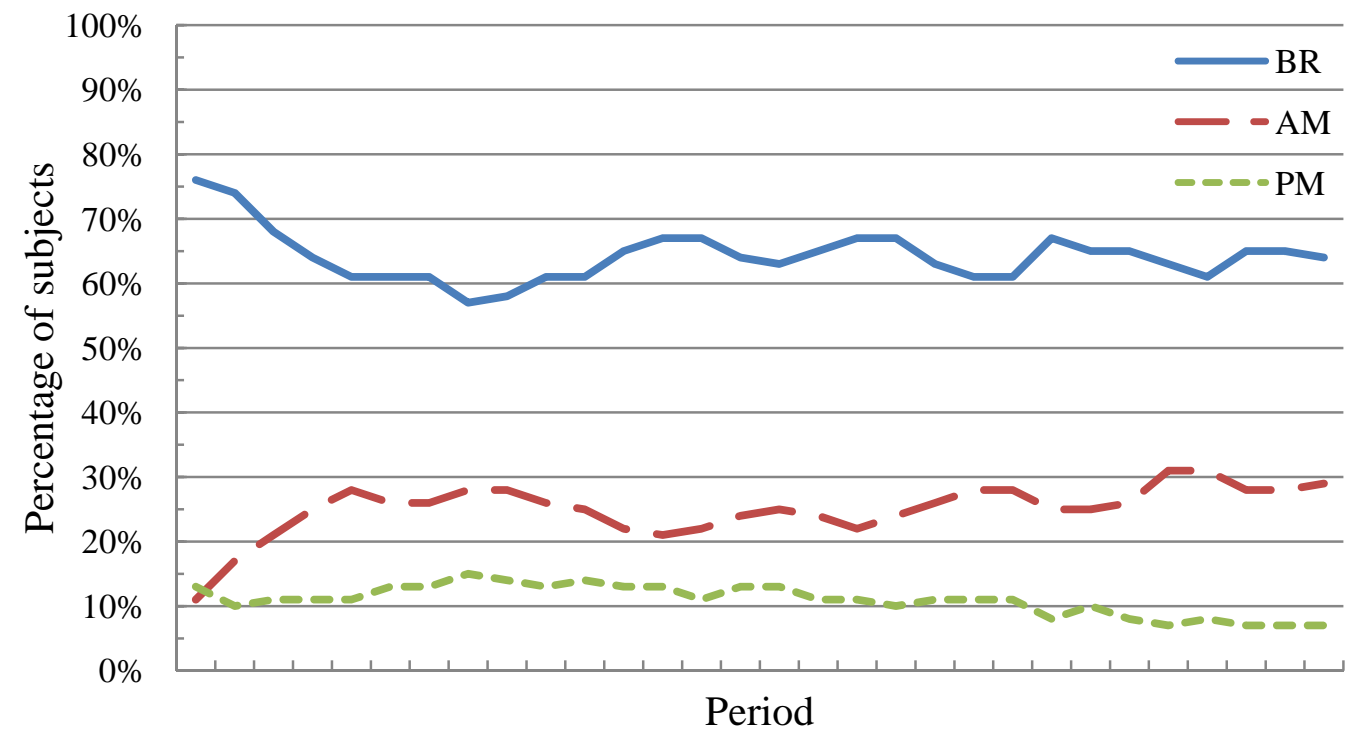

Figure 9: The estimated sequence of proportions of subjects using the three rules.

\footnotetext{
14 The natural way to explore hypothesis of this nature would be to model the transition probabilities as functions of the history of actions and payoffs. Unfortunately, there simply isn't enough variation in the rule switching to generate estimated transitional probabilities that have covariates.
} 
The dynamics of the estimated model suggests the rule adjustments mostly occur early in the experiment and involve decaying proportion of sophisticated sellers. In Figure 8, we present the sequence of estimated proportions of subjects for each period in time, $\mu_{r t}$. Notable here is that initially seventy-six percent of the subjects are estimated to be using a strategic best-response strategy but that proportion over the course of thirty auctions falls to sixty-four percent. Meanwhile we see an accordingly strong increase in the proportion of $A M$ bidders from eleven percent to twenty-nine percent; and the percentage of $P M$ bidders falls from thirteen to nine percent. In this estimated rule switching model, would the subjects learn to be more sophisticated in a much longer sequence of auctions? Actually, the prospect of further learning is not strong. The limiting distribution of the matrix of transition probabilities is $\Pi_{\infty}=(0.28,0.10,0.62)$. Inspection of Figure 8 shows that the experiment has already converged close to these values.

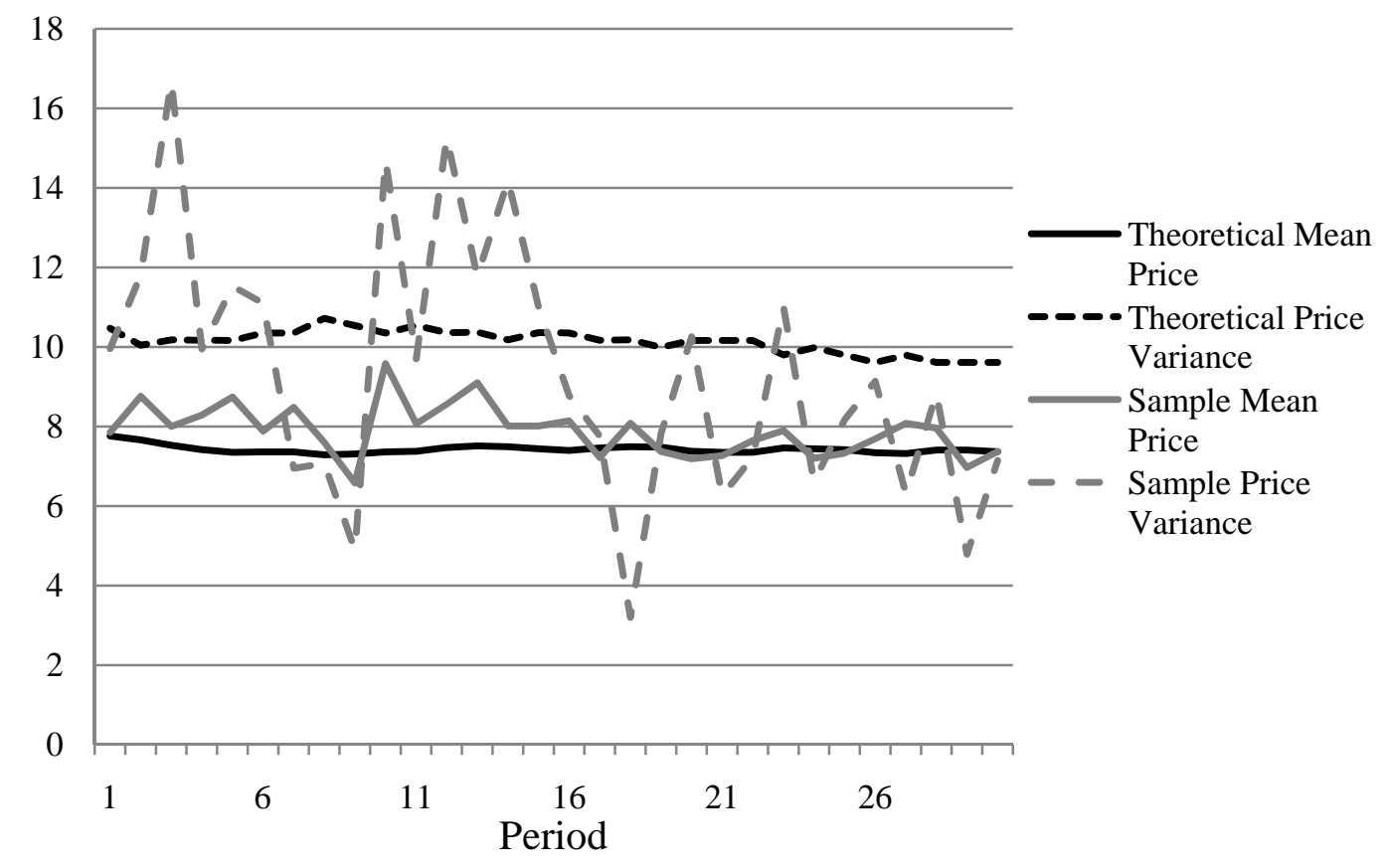

Figure 10: Empirical versus theoretical mean and variance of price Theoretical values calculated using HMM parameter estimates.

Does this estimated model explain the deviations of price performance from the predictions of the risk neutral Nash equilibrium model? As discussed earlier, the sample mean has a small but statistically significant negative time trend, while the sample variance does appear to have a negative but not significant time trend. Figure 10 depicts, the theoretical mean and variance calculated using the estimated rule switching model parameters as well as the 
empirical measurements of price mean and variance. Visual inspection suggests that the rule switching model qualitatively captures the values and trend, and I find this encouraging. However, regressions of the observed averages on the theoretical predictions aren't significant although the coefficients are close to one in both cases. For this experiment the time variance of price average and variance dynamics adjust too little over time to provide a dynamic model a strong opportunity to explain, or fail to explain, these dynamics. There is a plan to run future experiments that hopefully will create such an opportunity.

\section{Discussion}

Our experiments provide a clear demonstration of the relative performance of the FPA versus the EA in a commodity procurement setting. In light of these results, any procurement organization should proceed cautiously when initiating a reverse auction strategy with the purchase of commodities. From the procurement organization's perspective EAs not only deliver higher expected prices, but also greater price variability. It is worth noting that increased price variability, has a negative impact beyond a procurement organization's distaste of increased price uncertainty. Recent research studies, Jap [2007] and Haruvy and Jap [2008], have documented that relationship between suppliers and buyers is negatively impacted by the adoption of the reverse auction. The documented increase in price variance can be at least a partial source of this seller animosity.

Beyond summarizing our results, we want to consider why our results contradict the frequently reported successes in first trials of reverse auctions? The issue of price variance is again a possible source. Higher price volatility generates a larger number of "great" successes when switching from the FPA to the EA, of course there will also be more spectacular failures as well. If there is a bias in reporting successful versus negative outcomes - for examples see AnWen Chan et al (2004) and Graham, Harvey, and Rajgopal (2005) - then we should see more reports of successful initial reverse auctions. However, instead of just assuming there is a reporting bias, let's consider how our commodity sourcing experiment might differ from those in the field.

In our study we fixed the number of potential suppliers and made several strong assumptions; relaxing any of these could lead to different outcomes. In practice, it's likely that when initiating reverse auction sourcing variables other than the auction format change. Such esourcing efforts typically include attempts to increase the number of qualified participating 
suppliers. It's clear in both the FPA and the reverse auction increasing the number of suppliers will reduce price, but all of our theories suggest that the FPA will still retain its advantages.

In our analysis we assume suppliers independently draw costs from the same distribution. If we relax that assumption, for example one supplier has a clear advantage in location and likely lower cost, and then the better sourcing practice is not so evidently clear. Theoretical studies, such as Maskin and Riley (2000) and Cantillon (2008), predict that whether a EA will lead to lower price depends crucially on the distributions of costs. Experiments such as Guth et al(2005) reveal that subjects overbid, not realizing how competitively strong their positions are at times, from theoretical bid functions in such environments.

One area where reverse auctions do show much promise is in the procurement of goods for which price is not the only differing attribute between suppliers. Researchers have studied two cases: when non-price attributes are exogenous and when they are determined within the auction. Engelbrech-Wiggans, Haruvy, and Katok (2007) find significant gains to the procurement official when suppliers bid on price, and then the buyer chooses the winner versus awarding the contract to the lowest bidder. The performance of the buyer determined winner auction versus the FPA in these setting is studied in Haruvy and Katok (2008), and they find the FPA is better if suppliers have accurate and precise information regarding the quality of other sellers. On the other hand, Shachat and Swarthout (2010), find that an EA with buyer assigned bidding credits can provide better outcomes than the FPA for both suppliers and sellers. There is also a large and promising literature on successful reverse auction examples where the quality is determined within the reverse auction, for example Chen-Ritzo et al (2005) and Parkes and Kalagnanam (2005).

In summary, the knowledge gained in our study can inform procurement organizations that commodity buys may not be the optimal place to start a reverse auction initiative. Also, for the literature on sealed bid auctions our procurement framing permitted a new identification of bidding heterogeneity across individuals. Further investigations of what drives the evolution of this rule of thumb heterogeneity and what other types of environments does it exists are needed. Through the use of game theoretic arguments and controlled laboratory experiments were able to justify our results. Perhaps practitioners will see the value of the tandem use of these tools is for addressing other procurement problems. 


\section{References}

Abbas, Ali E. and Il-Horn Hann. "Measuring Risk Aversion in a Name-Your-Own-Price Channel,” Decision Analysis 7, 1 (March 2010), pp: 123-136.

Amaldoss, Wilfred, Teck-Hua Ho, Aradhna Krishna, Kay-Yut Chen, Preyas Desai, Ganesh Iyer, Sanjay Jain, Noah Lim, John Morgan, Ryan Oprea, and Joydeep Srivasatava."Experiments on strategic choices and markets," Marketing Letters, vol. 19, no.3 ( December 2008): 417-429.

An-Wen Chan, Asbjørn Hróbjartsson, Mette T. Haahr, Peter C. Gøtzsche, and Douglas G. Altman. "Empirical evidence for selective seporting of outcomes in randomized trials: comparison of protocols to published articles." The Journal of the American Medical Association 291 (May 2004): 2457-2465.

Barrett, Garry F. and Stephen G. Donald, "Consistent Tests for Stochastic Dominance," Econometrica, vol. 71 no. 1, (January 2003): 71-104.

Berg, Joyce, John Dickhaut, and Kevin McCabe, "Risk Preference Instability Across Institutions: A Dilemma," Proceedings of the National Academy of Sciences, (102)11, pp 4209-4214, 2005.

Bradlow, Eric T. and Young-Hoon Park. "Bayesian Estimation of Bid Sequences in Internet Auctions Using a Generalized Record-Breaking Model," Marketing Science, vol 26, no. 2 (March-April 2007): 218 - 229.

Cantillon, Estelle. "The effect of bidders' asymmetries on expected revenue in auctions." Games and Economic Behavior 62, no. 1 (January 2008): 1-25.

Chafkin, Max. "Reverse auctions: a survival guide." Inc. May 2007.

Chan, Tat Y., Vrinda Kadiyali, and Young-Hoon Park. "Willingness to Pay and Competition in Online Auctions," Journal of Marketing Research, vol. 44, no. 2 (2007): 324-333.

Chen, Kay-Yut and Charles Plott, "Nonlinear Behavior in First Price Sealed Bid Auctions", Games and Economic Behavior, 25:34-78, 1998.

Chen-Ritzo, Ching Hua, Terry P. Harrison, Anthony M. Kwasnica, and Douglas J. Thomas. "Better, faster, cheaper: an experimental analysis of a multiattribute reverse auction mechanism with restricted information feedback." Management Science 51, no. 12 (December 2005): 17531762.

Coppinger, Vicki, Vernon L. Smith and John Titus. "Incentive and behavior in english, dutch, and sealed-bid auctions." Economic Inquiry 18 (January 1980): 1-22.

Cox, James and R.L. Oaxaca, "Is bidding behavior consistent with bidding theory for private value auctions?" in R. M. Issac, edited, Research in Experimental Econmics Vol. 6, JAI Press, Greenwich. JAI Press, (1996): pp 138--148. 
Cox, James C., Bruce Roberson, and Vernon L. Smith. "Theory and behavior of single object auctions." In Reseach in Experimental Economics, edited by Vernon L. Smith, 537-579. Greenwich: JAI Press, 1982.

Dholakia, Utpal M. and Itamar Simonson. "The Effect of Explicit Reference Points on Consumer Choice and Online Bidding Behavior," Marketing Science 24, 2 (Apr. 2005): 206-217

Elmaghraby, Wedad. "Auctions within E-sourcing events." Production and Operations Management, 16, no. 4 (2007): 409-422.

Engelbrecht-Wiggans, Richard and Elena Katok. "Regret in auctions: theory and evidence," Economic Theory, vol. 33, no. 1 (2007): 81-101.

Fay, Scott. " Partial-Repeat-Bidding in the Name-Your-Own-Price Channel," Marketing Science, vol. 23, no. 3 (Summer 2004): 407-418.

Filiz, Emel, and Erkut Y. Ozbay. "Auctions with anticipated regret: theory and experiment." American Economic Reveiw 97, no. 4 (September 2007): 1407-1418.

Goeree, Jacob K., Charles Holt, and Thomas Palfrey,"Quantal Response Equilibrium and Overbidding in Private-Value Auctions," Journal of Economic Theory, Elsevier, vol. 104(1), pages 247-272, May 2002.

Graham, John R., Harvey, Campbell R. and Rajgopal, Shivaram. "The economic implications of corporate financial reporting." Journal of Accounting and Ecnomics 40 (December 2005): 3-73.

Guth, Werner, Radosveta Ivanova-Stenzla, and Elmar Wolfstetter. "Bidding behavior in asymmetric auctions: an experimental study." European Economic Review 49, no. 7 (October 2005): 1891-1913.

Haruvy, Ernan, , Peter T. L. Popkowski Leszczyc, Octavian Carare, James C. Cox, Eric A. Greenleaf, Wolfgang Jank, Sandy Jap, Young-Hoon Park and Michael H. Rothkopf.

"Competition Between Auctions," Marketing Letters, vol. 19, no 3-4 (Dec. 2008): 431-448.

Haruvy, Ernan and Elena Katok. "An Experimental Investigation of Buyer Determined Procurement Auctions." Unpublished manuscript. Pennsylvania State University (2008).

Holt, Charles A. "Competitive bidding for contracts under alternative auction procedures." Journal of Politcial Economy, (88) 1980: 433-445.

Hui, Sam K., Peter S. Fader, and Eric T. Bradlow. "Path Data in Marketing: An Integrative Framework and Prospectus for Model Building," Marketing Science, vol. 28, no.2 (March-April 2009): 320 - 335.

Jap, Sandy D. "Online Reverse Auctions: Issues, Themes, and Prospects for the Future," Journal of the Academy of Marketing Science, Vol. 30, No. 4, 506-525 (2003) 
Jap, Sandy D. "The impact of online reverse auction design on buyer-supplier relationships." Journal of Marketing 71, no. 1 (2007): 146-159.

Jap, Sandy and Ernan Haruvy. "Interorganizational relationships and bidding behavior in industrial online reverse auctions." Journal of Marketing Research 45, no. 5 (2008): 550-561.

Jap, Sandy D., and Naik Prasad. "BidAnalyzer: a method for estimation andsSelection of dynamic bidding models." Marketing Science 27, no. 6 (2008): 949-960.

Kagel, John H., "Auctions: A Survey of Experimental Research," In The Handbook of Experimental Economics, ed. John H. Kagel and Alvin E. Roth. Princeton: Princeton University Press (1995).

Kagel, John H. and Dan Levin, “Auctions: A Survey of Experimental Research 1995-2008” to appear The Handbook of Experimental Economics, vol 2 with D. Levin (2010).

Kagel, John H. and Dan Levin. "Auctions:experiments." In The New Palgrave Dictionary of Economics, edited by Steven N. Durlauf and Lawrence E. Blume. Palgrave McMillan, 2009.

Kinney, Sam. "RIP Fixed Pricing: The Internet is on its way to "marketizing everything"." Business Economics, April 2000: 39-44.

Krishner, Vijay. Auction Theory. London: Academic Press, 2002.

Levy, Haim. "Stochastic Dominance and Expected Utility: Survey and Analysis," Management Science, Vol. 38, No. 4, April 1992, pp. 555-593

Ledyard, John O. "The scope of the hypothesis of Bayesian equilibrium." Journal of Economic Theory 39, no. 1 (June 1986): 59-82.

Maskin, Eric, and John G. Riley. "Asymmetric auctions." Review of Economic Studies 67, no. 3 (July 2000): 413-438.

Netzer, Oded, James M. Lattin, and V. Srinivasan. "A Hidden Markov Model of Customer Relationship Dynamics," Marketing Science, vol. 27, no. 1 (March-April 2008): 185 - 204.

Neugebauer, Tibor, and Reinhard Selten. "Individual behavior in first price auctions: the importance of informational feedback in computerized experimental markets." Games and Economic Behavior 54, no. 1 (January 2006): 183-204.

Park, Young-Hoon and Eric T. Bradlow. "An Integrated Model for Bidding Behavior in Internet Auctions: Whether, Who, When, and How Much, "Journal of Marketing Research, vol. 42, no. 4 (November 2005): 470-482.

Parkes, David C., and Jayant Kalagnanam. "Models for Iterative Multiattribute Procurement Auctions." Management Science 51, no. 3 (March 2005): 435-451.

Porter, Anne Millen. "E-Auction Playbook." Purchasing.com. 2001. 
Rabiner, Lawrence R. "A Tutorial on Hidden Markov Models and Selected Applications in Speech Recognition," in Proceedings of the IEEE, vol. 77 (1989), pp. 257-286.

Reily, David. "Auctions on the Internet: What's Being Auctioned, and How?"

The Journal of Industrial Economics, Vol. 48, No. 3 (Sep., 2000), pp. 227-252

Seshadri, Sudhindra, Kalyan Chatterjee, and Gary L. Lilien, "Multiple Source Procurement Competitions," Marketing Science, Vol. 10, No. 3 (Summer, 1991), pp. 246-263

Shachat, Jason, and J. Todd Swarthout." Procurement Auctions for Differentiated Goods,"Decision Analysis 7, 1, (March 2010), pp. 6-22

Stein, Andrew, Paul Hawking, and C. Wyld David. "The 20\% Solution?:A case study on the efficacy of reverse auctions." Management Research News 26, no. 5 (2006): 1-20.

Yao, Song and Carl F. Mela. "Online Auction Demand," Marketing Science, vol. 27 No. 5 (September-October 2008): 861 - 885.

Vickrey, William. "Counterspeculation, Auctions , and Competitive Sealed Bid Tenders." Journal of Finance, 16 (1961): 8 -37. 